\title{
Functional disorders in patients with unbalanced occlusion and articulation
}

\author{
Hristina Arnautska ${ }^{1}$, Desislava Konstantinova', \\ Mariana Dimova ${ }^{2}$, Ivan Gerdzhikov ${ }^{3}$, Tihomir \\ Georgiev".
}

1. Assistant Professor at the Department of Prosthetic Dental Medicine and Orthodontics, Faculty of Dental Medicine, Medical University Varna;

2. Associate Professor at the Department of Prosthetic Dental Medicine, Faculty of Dental Medicine, Medical University Sofia;

3. Assistant Professor at the Department of Prosthetic Dental Medicine, Faculty of Dental Medicine, Medical University Sofia;

4. Associate Professor, Head of Educational and Research Sector in Oral Surgery, Department of Oral and Maxillofacial Surgery, Faculty of Dental Medicine, Medical University Varna

\begin{abstract}
The impaired balance in articulation and occlusion can be due to anatomical or iatrogenic causes, nevertheless, it always violates the coordination of morphological structures of the masticatory apparatus and their function. The authors of the present paper aim to explore all available literature in an attempt to analyze mastication and speech functions in patients with unbalanced occlusion and articulation, the result of dentofacial deformities and/or missing teeth and inadequate prosthetic treatment.
\end{abstract}


Materials and Methods: The selection of analysed database was carried out gradually by searching out electronic databases: Pub-Med (htpp://www.pubmed.com), Science-Direct (http://www.sciencedirect.com/), Scopus (http://www.scopus.com/) and manual search in four languages: Bulgarian, Russian, English and German.

Results: The study of 30 sources has revealed that occlusion-articulation imbalance is indicative for the development of normal chewing cycles, correct speech and diction. An impaired masticatory function has negative impact on proper nutrient intake for the patient.

Conclusion: Patients with malocclusion and/or varying degrees of edentulism or having undergone prosthetic treatment inconsistent with the three medico-biological criteria, exhibit different functional disorders compared to patients who do not need that treatment.

Keywords: functional disorders, speech disorders, eating and masticatory disorders

\section{Introduction}

The normal function of the masticatory apparatus involves coordination between many structures, including teeth, salivary glands, the tongue and chewing muscles. Impairment in any of these organs can lead to chewing and speech disorders. Missing teeth and unbalanced broken occlusion and articulation may result in multicausal problems in aesthetics, phonetics, chewing and swallowing. Few studies explore the impact of occlusal relationships on the chewing and speech functions..

\section{Aim}

On the basis of literature data the authors of the present study attempt to analyze impaired chewing and speech functions in patients with unbalanced occlusion and articulation due to dentofacial deformities and/or missing teeth and an inadequate prosthetic treatment.

\section{Material and Methods}

For the purposes of retrieving literature data a thorough analysis was initially carried on currently available relevant literature.

Search Method: Over the period March 2015 - October 2015 the search was performed in stages based on the electronic databases Pub-Med (htpp: //www.pubmed.com), Science-Direct

(http://www.sciencedirect.com/), Scopus (http: / /www.scopus.com/) in English, German and Russian. Parallel to that search a manual literature search was implemented for paper sources in Bulgarian, English, German and Russian at the University Libraries in Varna and Sofia. The following key words were used for the purpose: functional disorders, speech disorders, eating and chewing disorders. The search returned 214 results from various sources. Additional criteria were then applied; as a result 30 articles were selected as ones that represented original content and included an objective examination of the dysfunction.

Impairment of the occlusal-articulation relationships as a result of compromised integrity of the teeth rows or as a result of inadequate prosthetic treatment is often associated with the development of functional 
pathology of the masticatory apparatus $(1,2,3)$, possible impairment of other adjacent structures or systems and their neurogenic hormonal regulation, which in turn reflects the quality of life (4). Edentulism (partial or complete) is typically linked to age, education, social background, financial status and smoking (5). The importance of adequate prosthetic treatment has been discussed by a number of authors (6). Taichhi et al. have carried out research in order to clarify the role of artificial dental arches for the process of swallowing in edentulous patients, the role of tongue for the smooth passage of food bolus to the oropharynx and the lifting of the larynx when placing the mandible in the intercuspal position. Edentulous patients tend to reduce the intake of fruits, vegetables and fiber and increase the intake of saturated fat compared to similar patients with recovered dentition $(7,8,9)$. The functional difficulties associated with eating are to be regarded as the primary incentive for prosthetic recovery of missing teeth, otherwise prosthetic treatment per se would have no effect on positive dietary changes $(10,11)$.

In patients with orthodontic deformities masticatory efficiency is determined by the available number of teeth in occlusion. The first permanent molar is defined as the most important tooth for chewing efficiency and function (12). Therefore, proper occlusal relationships and proper contact relations are of great significance for the normal chewing process. An orthodontic treatment for the improvement of occlusal relationships resulting in masticatory improvement is definitely also associated with enhanced aesthetics for these patients (13).

The breach in the masticatory process when there are orthodontic deformities is closely linked to impaired occlusal contacts in the sagittal and transverse planes. Significant deviations from normal chewing movements are also caused by the change in muscle tone and the myoelectric potential of the Masseter muscle and the Temporalis muscle responsible for mastication. The application of orthodontic treatment combined with miogymnastics lead to improved muscle tone and masticatory efficiency (14).

A research conducted by Ngom et al. (13) reveals that the change in occlusal relationships following an orthodontic treatment leads to a significant improvement of mastication and food digestion. Children with distal occlusion, aged 6 - 15, have masticatory efficiency reduced to $15-20 \%$; those with medial occlusion, respectively to 15 - 30\%; children with occluded front - 16 - $66 \%$; and those with deep occlusion - 24 - 54\%. Picinato-Pirola et al. (15) have established a statistically significant difference in masticatory efficiency for patients with class I, class II and III dentofacial deformities. There is no statistically significant difference between the two groups with sagittal skeletal deformities, which is a proof that the change in position of the lower jaw is associated with altered occlusal relationships as well as masticatory muscles tone. This makes it extremely difficult to treat those patients in mature age and complicates the prosthetic treatment of the dentofacial apparatus.

A functionally complete occlusion and a prosthesis should comply with the requirements for chewing efficiency as well as the social need for proper speech and diction (16). According to Chierici G. et al. (1973) and H. D. Kimbal, H.J. Muyakens (1937), speech disorders are generally classified in two major groups: disorders linked to neurological diseases and disorders caused by masticatory apparatus dysfunction and its rehabilitation. The functional relations between the tongue and the palate, on one hand, and the tongue and dental rows, on the other hand, are affected by certain dentofacial deformities in dental rows, and by the presence of various prostheses and orthodontic structures $(17,18,19,20,21)$. 


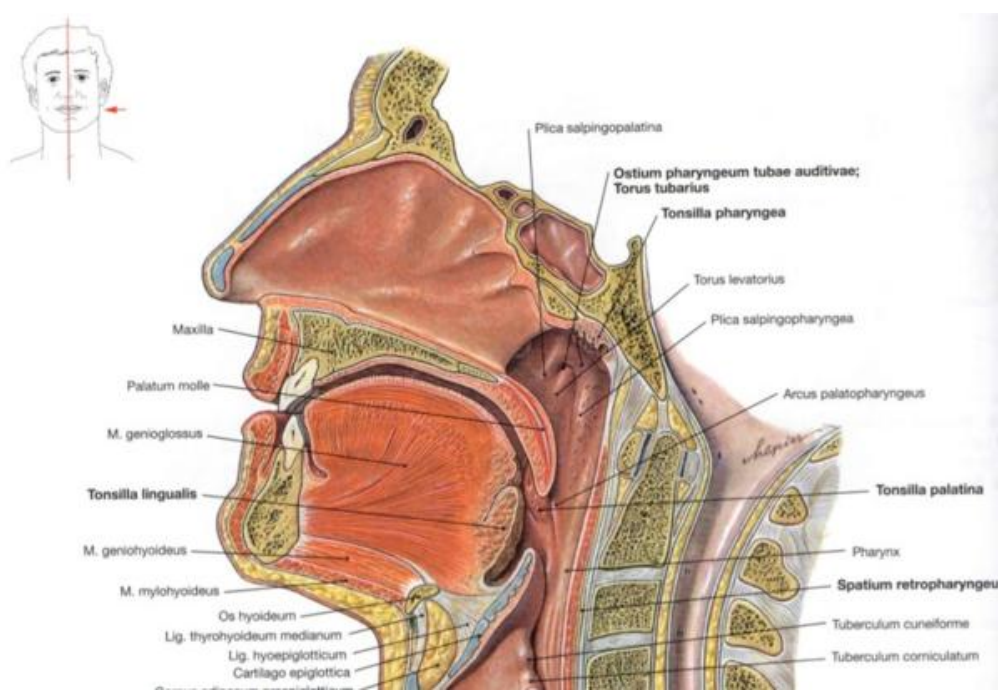

Figure 1 : Morphological structures of the masticatory apparatus (22)

There is a significant correlation between teeth position and proper sound-production. Despite numerous studies and attempts to explain the relationship between the two, the results have so far proved inconclusive. Research in this particular area started as early as Harold (23) who considered three possible mechanisms of interrelation: occlusal or skeletal abnormalities; the central nervous system being affected by genetic or metabolic components or structural disorders affecting articulation.

In a study exploring occlusal and speech deviations in a large group of students, Fymbo $(24,25)$ found out that those with malocclusion exhibit significantly greater difficulty with the pronunciation of dental sounds, compared to a group with normal occlusal relationships. According to the author, more lisping can be seen in patients with open occlusion. A great number of authors conclude in their researches that the position of the tongue, the position of incisors and the tone of the Orbicularis oris muscle have a major role for deviations in sound-production.

Laine (26) examines the relationship between speech disorders and the size of the upper and lower jaw. He has established that the narrowing of the upper jaw and a deep palate lead to significant deviations in palatal consonants whereas changes in the lower jaw size are not essential for sound-production. In another study (27) the same author reveals that $2 / 3$ of surveyed patients with medial occlusion display speech disorders. This is related to the lower and rear position of the tongue and its loss of contact with the front of the palate and upper incisors. Unlike other studies, Laine (27) establishes more speech disorders in Class III patients with anterior crossbite compared to Class I patients with anterior open bite. In Class II, Division 1 patients, regardless of skeletal abnormalities, the tongue seems to adapt and, to a certain extent, compensates the speech disorder. However, in these patients there is a deviation in sounds, formed in the front of the palate and the alveolar ridges.

In Class III patients if deformities are moderate, major speech disorders have not been observed Bloomer(28). Laine (27) records deviations in the formation of palato-alveolar consonants related to a medial bite. Kessler (29) recognizes that treatment of occlusal relationships leads to speech improvement. Pahkala et al. (30) carried out tests with children between the age of 9 and 11 with orthodontic and speech 
disorders, dividing them into two groups: a group receiving treatment and a placebo group. Just two months later the group having occlusal relationships and teeth position treated, demonstrated speech improvement whereas the placebo group registered no effect.

Certain sounds are more sensitive to disorders in teeth and jaws position. It is essential to provide opportunity for the tongue to adapt and to compensate for sound-production, despite structural abnormalities in the oral cavity. It depends on the individual compensatory abilities of each patient. In his research Bloomer (1971) suggests the following summary of the correlation between orthodontic deformities and speech disorders.(12)

Normal structure + normal function $=$ normal speech

Structural deviation + adaptive function $=$ normal speech

Structural deviation + lack of adaptive function $=$ speech disorder

Normal structure + dysfunction $=$ speech disorder

Therefore, the study of patients must be assessed not only in terms of structural abnormalities, but also in relation to the extent of dysfunction. The treatment of patients ought to be conducted by both an orthodontist and a speech therapist for younger patients and by a team of an orthodontist, an orthopaedist and a speech therapist for adult patients. Thus, after restoring dental integrity, optimum results can be expected.

\section{Conclusion}

The literature review reveals that a patient with malocclusion, requiring orthodontic treatment, or an edentulous patient with a removable dental prosthesis display different functional disorders, compared to patients who do not need that treatment. The need for restoring a patient's masticatory and speech functions by adjusting the occlusion and articulation balance frequently requires an interdisciplinary approach. In order to meet the three medico-biological criteria (preventive, functional and aesthetic) in implementing the treatment plan, the expertise of orthodontists, prosthetists and relevant specialists is fundamental..

\section{References}

1. Ahlers MO, Jakstat HA. Klinische Funktionsanalyse. 4 erweiterte und aktualisierte Auflage. dentaConcept, Hamburg, 2011, 45.

2. John $\mathrm{M}$, Hirsch $\mathrm{C}$, Reiber $\mathrm{T}$, Dworkin. Translating the research diagnostic criteria for temporomandibular disorders into German: evaluation of content and process. J Orofac Pain. 2006; 20: 43-52.

3. Slavicek, R. Das Kauorgan. Functionen und Dysfunctionen, Gamma Medizinischwissenschaftliche Fortbildungsgesellschaft, Klosterneoburg, 2006; 544. 
4. John M, Reissmann D, Schierz O, Wassell R. Oral health-related quality of life in patients with temporomandibular disorders. J Orofac Pain. 2007; 21 (1): 46-54.

5. Talwar ., G. Malik, Oral health considerations for the elderly e problems and managemen strategies. Indian Journal of Dentistry 2013; 4(3) ; 145-151.

6. Taichi Imaizaki, Yasuhiro Nishi, Akihito Kaji, Eiichi Nagaoka. Roles of the artificial tooth arch during swallowing in edentates. Journal of Prosthodontic Research. 2010; 54 (1): 14-23. doi:10.1016/j.jpor.2009.08.002.

7. Johansson I, Tidehag P, Lundberg V, Hallmans G. Dental status, diet and cardiovascular riskfactors in middle-aged people in northern Sweden Community. Dentistry and Oral Epidemiology. 1994; 22: 431-436.

8. Joshipura K, Willett W, Douglass C. The impact of edentulousness on food and nutrient intake. Journal of the American Dental Association. 1996; 127: 459-467.

9. Lee JS Weyant RJ, Corby P, Kritchevsky SB, Harris TB, Rooks R et al. Edentulism and nutritional status in a biracial sample of well-functioning, community-dwelling elderly: the health, aging, and body composition study. American Journal of Clinical Nutrition, 2004; 79: 295-302.

10. Sandström B, Lindquist $L$. The effect of different prosthetic restorations on the dietary selection in edentulous patients. Acta Odontologica Scandinavica. 1987; 45: 423-428.

11. Sebring N, Guckes A, Li SH, McCarthy G. Nutritional adequacy of reported intake of edentulous subjects treated with new conventional or implant-supported mandibular dentures. Journal of Prosthetic Dentistry. 1995; 74: 358-363.

12. Manly RS, Hoffmeistr FS, Yurkstas A. Masticatory function of children with orthodontic disturbances. AJODO, 1954; 40 (10): 756-764.

13. Ngom PI, Diagne F, Aïdara-Tamba A, Sene A. Relationship between orthodontic anomalies and masticatory function in adults. AJODO, 2007; 131 (2): 216-222.

14. Papa Ibrahima Ngom, Falou Diagne,Adjaratou Wakha Aïdara-Tamba, and Abdou Sene Relationship between orthodontic anomalies and masticatory function in adults. Am J Orthod Dentofacial Orthop. 2007; 131: 216-222.

15. Picinato-Pirola MNC et al. Masticatory efficiency in class II and class III dentofacial deformities. Int J Oral Maxillofac Surgery. 2012; 41: 830-834 D.

16. Bogiatze D. Articulated speech, phonetics and dentures. Hell Stomatol Chron. 14, Athenai, 1970, 9-19.

17. Rutkowski KV. опросьи восст новления речи при полном зубном протеризов нии. Tashkent, Medicine, 1970. 
18. ichner K. Funktionale Gesichtspunkte zur Basisgestaltung von Modellgubprothese.Dtsch.Zahnarztl. Z. 29; 1974; 10: 930-937.

19. Kubota T, Yagi T, Tomonari H, Ikemori T, Miyawaki S., Influence of surgical orthodontic treatment on masticatory function in skeletal Class III patients. Journal of Oral Rehabilitation. 2015; 42 (10): 733-741.

20. Moynihana PJ, Elfekye A, Ellisa JS, Sealc CJ, Hylandf RM, Thomasona JM. Do implant supported dentures facilitate efficacy of eating more healthily?. Journal of Dentistry. 2012; 40 (10): 843-850.

21. Yamaguchi $\mathrm{H}$, Tanaka $\mathrm{Y}$ et al. Changes in oral functions and muscular behavior due to surgical orthodontic treatment. Bulletin of the Tokyo, Dental College. 1994; 35: 41-49.

22. Sobotta, Atlas of Human Anatomy, vol.3,15th Edition, 2011.

23. Harvold EP. Speech articulation and oral morphology. Am. Speech Hearing Assoc. 1970; report 5:69-75.

24. Fymbo LH. A study of the relation of malocclusion to articulatory defective speech, part 1 lowa State Dent J. 1956; 42: 288-294.

25. Fymbo LH. A study of the relation of malocclusion to articulatory defective speech, part 2 lowa State Dent J. 1957; 43: 8-13.

26. Laine T. Articulatory disorders in speech as related to size of the alveolar arches, EJO, 1986; 8 (3): 192-197.

27. Laine T. Malocclusion traits and articulatory components of speech. EJO. 1992; 14: 302-309.

28. Jonson N, Sandy J. Tooth position and speech - Is there a relationship?. Angle Orthod. 1999; 69 (4): 306-310.

29. Kessler HE. The speech of your young dental patients. Dental Survey. 1951.

30. Pahkala R, Laine T, Narhi M. Associations among different orofacial dysfunctions in 9-11 year olds. Eur J Orthod. 1995; 17: 497-503.

\section{Corresponding author:}

Dr. Hristina Arnautska, D.M.Sc.

Department of PDM and Orthodontics, Faculty of

Dental Medicine, Medical University-Varna

84 "Tsar Osvoboditel" Str., Varna

GSM: 0877599675

E-mail: tineia@yahoo.com 